\title{
Desigualdade e Informação Política: As Eleições Brasileiras de 2002*
}

Lucio R. Rennó

\section{INTRODUÇÃO}

$\mathrm{D}$ esigualdade e exclusão são traços marcantes da América Latina, tanto no passado quanto no presente. Caracterizada como o continente das distorções (lop-sided continent), a América Latina é uma das regiões do mundo em que as divisões entre ricos e pobres, agravadas por raça, etnia e gênero, são das mais profundas (Hoffman e Centeno, 2003; Korzeniewicz e Smith, 2000; Portes e Hoffman, 2003), e onde grande maioria da população detém uma parcela ínfima dos recursos financeiros e, em geral, está destinada a uma vida de dificuldades. Para piorar a situação, a voz dos excluídos é raramente audível. A longa história de exclusão econômica e social é, em si, um testemunho eloqüente de quão raramente as demandas populares alcançam o governo.

A falta de voz de grande parte da população também nos remete a uma das características da desigualdade na América Latina, seu caráter cumulativo. Desigualdades parecem se acumular através de distintas es-

\footnotetext{
*Este estudo foi desenvolvido durante um pós-doutorado em 2004 e 2005 no Latin American and Caribbean Studies Center da State University of New York - SUNY, Stony Brook. Agradeço ao financiamento da Fundação Rockefeller e a Paul Gootenberg, então diretor, pelo apoio e incentivo. Versões anteriores deste artigo foram apresentadas em diversas ocasiões. Sou grato aos comentários recebidos na Universidade de Columbia, New School for Social Research e Universidade do Arizona. Finalmente, agradeço aos pareceristas anônimos de DADOS. Os erros que persistem são de minha responsabilidade.
}

DADOS - Revista de Ciências Sociais, Rio de Janeiro, Vol. 50, nº 4, 2007, pp. 721 a 755. 
feras da vida, afetando a distribuição de diversos recursos. Segundo Charles Tilly (1998), é justamente o traço cumulativo das desigualdades que parece fortalecer sua persistência e durabilidade. Dessa forma, um tema central das ciências sociais latino-americanas hoje é investigar como desigualdades distintas se acumulam e se reforçam, gerando um ciclo de exclusão cada vez mais agudo. Este artigo dá um passo nessa direção, ao mapear as desigualdades na distribuição de informação política e participação eleitoral no Brasil e sua relação com outras fontes de desigualdade, como raça, gênero e classe econômica.

Um objetivo central do estudo é, portanto, testar se gênero, raça e renda afetam a distribuição de recursos políticos no Brasil. Mais especificamente, será avaliado se há distorções sistemáticas no acesso a informações políticas, utilizando dados de pesquisas de opinião pública longitudinais durante as eleições brasileiras de 2002. Embora existam muitas evidências de que raça, gênero e classe econômica afetam a distribuição de diversos recursos no Brasil, pouco se sabe sobre o impacto da desigualdade na esfera política e, principalmente, no que tange o acesso à informação ${ }^{1}$. Assim sendo, este artigo visa preencher essa lacuna existente na literatura.

Dado que o Brasil, assim como diversos outros países latino-americanos, está entrando em sua terceira década de governança democrática, descobrir as raízes da desigualdade política nos permite avaliar como democracia e desigualdade têm coexistido nesta parte do mundo. A democracia deveria diminuir a desigualdade, como apontam diversos estudos (Bollen e Jackman, 1985; Muller, 1988). Paradoxalmente, desigualdade e democracia têm convivido na América Latina, e, como dito anteriormente, é possível que o caráter cumulativo das desigualdades esteja na essência de sua durabilidade na região. Contudo, vale destacar que há progresso em algumas frentes. Por exemplo, mulheres e afro-descendentes obtiveram ganhos palpáveis nos últimos governos brasileiros em matéria de acesso a cargos e à universidade. Há políticas de ação afirmativa disseminadas por diversas esferas da União. Portanto, o momento é oportuno para avaliar se alguns dos ganhos alcançados nas esferas públicas e sociais, mesmo que modestos, afetam a dimensão político-eleitoral.

Na próxima seção, o enfoque é na discussão teórica sobre desigualdade e como ela pode afetar a informação política. Em seguida, descrevo o banco de dados. Na parte seguinte, Medindo os Níveis Informacio- 
nais e de Opinião, discuto questões de mensuração e, posteriormente, testo o impacto de diferentes tipos de informação política em duas formas concretas de participação eleitoral, decidir votar e escolher o candidato. A seção Desigualdade e Aquisição de Informação examina vieses na distribuição de informação política por raça, gênero e renda. Finalmente, a Conclusão resume os achados, discute implicações e sugere estudos futuros.

\section{DESIGUALDADE E INFORMAÇÃO POLÍTICA}

Desigualdade refere-se à distorção sistemática na distribuição de recursos entre grupos sociais (Tilly, 1998), e é gerada quando um determinado grupo detém o controle e monopoliza a alocação de um recurso, criando uma situação em que ele se beneficia do acesso ao recurso, excluindo os demais. Historicamente, alguns grupos tiveram o acesso a diversos recursos seguidamente barrados. Em alguns casos, as clivagens étnicas definem as fronteiras da desigualdade, em outros, a raça é que define os incluídos e os excluídos. A classe, seja ela baseada na riqueza, no status social ou em casta, é um dos mecanismos mais marcantes da exclusão. Na maioria das sociedades, o gênero também é um elemento constante de diferenciação entre os que possuem e os despossuídos. Para piorar, as desigualdades parecem ser cumulativas. Primeiro, aqueles que não têm acesso a um recurso, como renda e riqueza, também não têm acesso a outros recursos, como justiça, tecnologia, informação, moradia e atendimento de saúde de qualidade, bem como à voz política. Tilly (idem) refere-se a esse processo cumulativo como adaptação ou emulação, significando que as desigualdades se transmitem de um recurso para outro ${ }^{2}$.

Os recursos políticos podem ser claramente afetados por desigualdades duradouras. Entre os recursos políticos dos eleitores, a informação e o voto são elementos centrais de uma participação ativa na organização do governo. A quantidade de estudos sobre sofisticação política e escolha eleitoral é, por si só, um forte indicador da essencialidade dessas questões para a cidadania democrática. E, de fato, a discussão sobre a sofisticação política é uma pedra fundamental no estudo do comportamento eleitoral e psicologia política (Niemi e Weisberg, 2001). Os estudos pioneiros de Campbell et alii (1960) na Universidade de Michigan e de Lazarsfeld, Berelson e Gaudet (1944) na Universidade de Columbia geraram uma prolífica agenda de pesquisas que tem sido seguida por mais de meio século. Obviamente, a discussão sobre como a 
informação afeta a escolha eleitoral não é consensual, mas algumas hipóteses parecem ter sustentado testes empíricos robustos.

O primeiro ponto de consenso na literatura de ciência política é que, aparentemente, os eleitores não precisam estar inteiramente informados sobre a política para escolher um candidato ou participar de uma campanha. Não é necessário ter um conhecimento enciclopédico sobre a política para fazer escolhas sensatas (Lupia e McCubbins, 2000) ${ }^{3}$, visto haver uma abundância de informações resumidas sobre os candidatos que são suficientes para instruir os eleitores a respeito das preferências de políticas públicas e de suas posições sobre diferentes questões ${ }^{4}$.

O segundo ponto de consonância na literatura é que os atalhos informacionais são, não obstante, informação (Luskin, 2002), embora os eleitores ainda precisem ter algum conhecimento de política para que tais atalhos sejam eficazes. Quase todos os estudos sobre atalhos cognitivos concordam que, através deles, os eleitores devem poder identificar os candidatos, seja pelo nome ou por sua filiação política, saber se é um candidato à reeleição (incumbent) ou um desafiante, quem o apóia e o que cada partido representa. Os eleitores não precisam ter informações factuais detalhadas sobre a posição específica de um político em relação a um determinado tema, nem sobre qual foi seu voto, quando no cargo, em diferentes proposições, mas precisam, sim, ter acesso a instrumentos que sumarizem esse tipo de informação. A literatura parece concordar que os eleitores precisam de um mínimo de informação para $\operatorname{votar}^{5}$.

O terceiro ponto de crescente consenso na literatura é que esse mínimo de informação necessária para tomar decisões eleitorais e participar de eleições não está prontamente disponível para todos os eleitores. Isto recoloca a questão da desigualdade. Os atalhos informacionais não são igualmente distribuídos em toda a sociedade (Luskin, 2002; Delli Carpini e Keeter, 1996). A obtenção de informações depende de características ambientais, institucionais e históricas, bem como de traços individuais. Por exemplo, Lupia e McCubbins (1998) argumentam que os partidos políticos, para que sirvam de fonte de informação para os eleitores, devem estar vinculados a preferências de políticas públicas ou posições ideológicas específicas e devem ter marcas consolidadas (reputações) que o eleitorado possa distinguir. Em outras palavras, o impacto do partidarismo depende, em parte, dos fatores históricos que condicionam a força partidária. Os autores sustentam expressamente 
que o papel dos atalhos informacionais é condicionado pelas instituições (idem, 2000).

Por exemplo, quando a concorrência política está fragmentada entre vários candidatos, torna-se mais difícil obter até mesmo esse mínimo de informação necessária sobre todos os candidatos (Rahn, 1993; Bartels, 1993; Lau e Redlawsk, 2001; Rennó, 2006). Nos sistemas políticos em que o conjunto de opções é pouco claro ou mais complexo, "seja em razão do caos das instituições ou do enfraquecimento da ideologia", os eleitores terão mais dificuldade de entender a política (Sniderman, 2000:83, tradução do autor). Assim, certas configurações no ambiente político dificultam ainda mais a capacidade de compreensão dos eleitores.

Vários autores foram além e efetivamente mapearam os vieses sistemáticos na distribuição de informação com base nas desigualdades históricas (Delli Carpini e Keeter, 1996; Mondak e Anderson, 2004). Em outras palavras, as desigualdades na distribuição de recursos econômicos são transferidas e reforçadas pelas desigualdades na distribuição da informação e da voz políticas. Deve ficar claro que os vieses sistemáticos não são atribuíveis a características pessoais de membros do grupo desprivilegiado, mas a restrições que foram estruturalmente impostas a este grupo ao longo do tempo.

Presume-se que as desigualdades na informação política refletem desigualdades que afetam outros recursos, ainda que tal afirmação não tenha sido completamente testada na América Latina, pois se sabe muito pouco sobre o papel da informação nas eleições neste continente e como a variação ambiental pode afetar sua distribuição.

O Brasil é um caso particularmente interessante para o estudo de informação e desigualdade, visto que, infelizmente, diversas formas persistentes de desigualdade afetam a vida cotidiana dos cidadãos brasileiros. A raça sempre foi um fator central de definição das relações sociais e econômicas, havendo evidências irrefutáveis de que é um determinante cardinal de discriminação no sistema educacional, nos tribunais e no mercado de trabalho, embora pouco se saiba sobre suas implicações no âmbito político ${ }^{6}$. A discriminação por gênero também é um problema fundamental do Brasil contemporâneo (Lovell, 2000), e tanto é assim que foram estabelecidas quotas partidárias com base nesse critério para a nomeação de candidatos para a Câmara dos Deputados. Apesar disso, o número de mulheres eleitas para cargos políticos é mui- 
to baixo, em comparação com sua participação na população. Em outras áreas, as mulheres têm obtido ganhos impressionantes, como no mercado de trabalho e no sistema educacional. Há, porém, evidência abundante em vários países diferentes de que existe um enorme hiato de gênero que favorece os homens, em se tratando da distribuição de informação política (Mondak e Anderson, 2004). Finalmente, a renda também parece ser um fator essencial de diferenciação entre brasileiros (Andrews, 1996). Os pobres têm uma perspectiva limitada de mobilidade social e pouco acesso a fontes distintas de informação; seu nível de educação é mais baixo do que o dos ricos e o acesso às melhores escolas é mais limitado. É razoável supor que os pobres também tenham níveis mais baixos de informação.

Dentre os aspectos positivos, o Brasil mostrou avanços marcantes no sentido de facilitar o acesso à informação política. Existem no país vários jornais e emissoras de televisão, sendo estas últimas facilmente acessíveis a quase toda a população. Recentemente, a cobertura tem sido equilibrada e imparcial, e não há indicação de que a mídia tenha sido significativamente tendenciosa em relação a um candidato ou tema específico nas eleições de 2002, em grande parte porque as regras sobre a cobertura de campanhas estavam mais rigorosas do que em eleições anteriores. Em pleitos passados, houve indícios de que a Rede Globo de Televisão, a maior emissora do país, favorecia determinados candidatos (Lima, 1993; Miguel, 1999). Em 2002, não houve acusações desse tipo. A análise de conteúdo dos dois principais canais de notícias no país (ver dados da Tabela 1) confirma que a cobertura da mídia foi, no geral, equilibrada ${ }^{7}$.

Tabela 1

Tempo Alocado (Medido em Segundos) e Número de Histórias por Candidato em Telejornais: Brasil 2002

\begin{tabular}{l|c|c}
\hline & Soma & Média \\
\hline Segundos alocados a José Serra & 39.035 & 128.40 \\
Segundos alocados a Luiz Inácio Lula da Silva & 36.969 & 121.61 \\
Segundos alocados a Ciro Gomes & 34.006 & 111.86 \\
Segundos alocados a Anthony Garotinho & 32.110 & 105.63 \\
\hline Número de histórias que mencionam José Serra & 444 & 1.46 \\
Número de histórias que mencionam Luiz Inácio Lula da Silva & 432 & 1.42 \\
Número de histórias que mencionam Ciro Gomes & 361 & 1.19 \\
Número de histórias que mencionam Anthony Garotinho & 326 & 1.07 \\
\hline
\end{tabular}

Fonte: Pesquisa Eleitoral em Duas Cidades Brasileiras, coordenada por B. Ames, A. Baker e L. Rennó, Universidade de Pittsburgh/National Science Foundation, 2002.

N: 304 Segmentos de Televisão. 
Além disso, as regras eleitorais estipulam que, no período que antecede as eleições, todos os candidatos tenham acesso gratuito a programas de televisão e rádio. O Horário Gratuito de Propaganda Eleitoral - HGPE destina aos partidos uma hora diária em televisão e rádio, e a divisão dos minutos é baseada no número de cadeiras de cada partido político na Câmara dos Deputados. Esta é claramente uma tentativa de democratizar o acesso à informação e reduzir o impacto do financiamento de campanhas nas eleições. A pergunta então é se esses avanços tiveram efeito na eqüidade da distribuição da informação na sociedade.

\section{DADOS: ESTUDO DE PAINEL DE DUAS CIDADES}

Para mapear os vieses sistemáticos na distribuição da informação no Brasil, este artigo se baseia em um conjunto único de dados de opinião pública, resultantes de um estudo de painel realizado em duas cidades brasileiras de médio porte durante as eleições de 2002, que contém informações no âmbito individual, de bairro e da cidade. O primeiro ciclo de entrevistas ocorreu em março e abril, antes do início da campanha, para obter, como marcos de referência, medidas da informação anteriores à exposição à campanha eleitoral. O segundo foi implementado em setembro, antes dos primeiros debates presidenciais e do início do HGPE. O terceiro ciclo ocorreu em outubro, entre o primeiro e o segundo turno das eleições para presidente e governador, e, portanto, permite medir o nível final de informação dos eleitores, após terem sido expostos a toda a campanha. Dessa forma, o banco contém dados individuais para os mesmos eleitores em momentos distintos do período eleitoral.

O desenho da pesquisa também apresenta variação espacial. As duas cidades escolhidas (Juiz de Fora, Minas Gerais e Caxias do Sul, Rio Grande do Sul) oferecem características distintas no ambiente político, ao mesmo tempo em que são relativamente semelhantes em termos socioeconômicos e demográficos. Assim sendo, aplica-se um desenho comparativo de sistemas similares na escolha dos casos.

Juiz de Fora é uma cidade em que os partidos políticos são mal organizados e com fracas distinções ideológicas. Ademais, as eleições para deputado federal são bastante complexas, com um número muito alto de candidatos concorrendo ao voto local. Caxias do Sul tem uma longa história de profunda clivagem ideológica entre os partidos de esquerda e direita. Esta divisão remonta pelo menos ao primeiro período de- 
mocrático, de 1945 a 1964, no qual havia um claro choque entre os partidários do Partido Trabalhista Brasileiro - PTB, de um lado, e os adeptos de todos os outros partidos, do outro. Durante a ditadura militar, a cidade se dividia entre o Movimento Democrático Brasileiro - MDB, o partido de oposição, e a Aliança Renovadora Nacional - Arena, o partido que apoiava o governo militar. Finalmente, com a redemocratização após 1986, a cidade manteve sua tradição de bipolaridade, desta vez definida entre pró e contra Partido dos Trabalhadores - PT). O aspecto interessante em Caxias do Sul é que seu sistema político tem partidos de esquerda e de direita bem estruturados e uma clara divisão ideológica que reproduz as fronteiras das classes econômicas. Os eleitores pobres apóiam o PT, e os mais ricos, os partidos de direita.

A variação no ambiente político entre as duas cidades permite testar como os diferentes contextos políticos podem atenuar ou intensificar vieses na distribuição da informação. Como dito anteriormente, as características ambientais parecem abalar a compreensão da política. É plausível conjecturar que os ambientes podem afetar os vieses na distribuição da informação, o que exige uma análise comparativa de como diferentes contextos interferem nos hiatos informacionais.

Além da variação entre as cidades, o conjunto de dados também incluiu os bairros como um nível de análise (Huckfeldt e Sprague, 1995). Foram realizadas cerca de 100 entrevistas em 22 bairros selecionados, usando uma amostra probabilística estratificada que permitisse a construção de indicadores agregados das características dos bairros. A amostra total reúne em torno de 2.500 entrevistas por ciclo em cada cidade, totalizando mais de 14.000 entrevistas nos três ciclos.

\section{MEDINDO OS NÍVEIS INFORMACIONAIS E DE OPINIÃO}

É importante, antes de analisar o impacto da informação política em escolhas eleitorais e participação nas eleições, definir como o conceito será mensurado. A informação política refere-se a quanta informação factual os eleitores têm sobre política (Delli Carpini e Keeter, 1996). Quando se utilizam dados de pesquisas, isso é medido pela simples contagem de respostas corretas em um breve teste. Outras estratégias de pesquisa incluem avaliações externas do conhecimento do entrevistado sobre política, geralmente feitas pelos entrevistadores (Bartels, 2005), e indicadores que não se referem a dados factuais precisos e concretos, mas a fatores que dependem da opinião dos entrevistados sobre 
certos tópicos, i.e., opinionation. Alguns tipos de opinião refletem a percepção do sistema político, que, em sua essência, baseia-se na informação. De fato, Delli Carpini e Keeter (1996) descobriram que a formação de opiniões depende da informação. Portanto, opinionation, expressar uma opinião, é também sinalização de conhecimento e sofisticação política.

As diferentes estratégias de mensuração estão relacionadas a distintas conceitualizações dos tipos de informação que os eleitores usam nas eleições. Alguns eleitores podem ser generalistas, saberem um pouco sobre várias questões políticas distintas. Outros podem ter maior conhecimento de temas específicos, serem especialistas em certas áreas ${ }^{9}$. As avaliações externas dos níveis de informação do entrevistado não são específicas em relação a uma dada questão, mas determinam quão informados estão os eleitores sobre todos os assuntos. É um indicador de conhecimento geral. Por outro lado, respostas para itens sobre tópicos específicos são uma forma muito mais focada de informação e uma indicação de que o entrevistado é um especialista em um determinado assunto.

Esses dois tipos de informação foram operacionalizados neste estudo, seguindo as tendências gerais da literatura. A informação geral é operacionalizada por avaliações, feitas pelo entrevistador, dos níveis de informação dos entrevistados (Informação Generalizada) ${ }^{10}$. A informação específica aqui se refere a determinado conhecimento sobre os protagonistas no processo eleitoral e é identificada por um índice da capacidade dos eleitores de citar os candidatos para os diferentes cargos (Conhece os Nomes dos Candidatos; alpha $=0,77$ ) e por um índice de informação sobre os deputados federais (Informação sobre Deputados Federais; alpha = 0,65). Essas perguntas são baseadas em informações factuais sobre os principais atores nas eleições e não dão margem para especulação.

Opinionation, por outro lado, refere-se à capacidade dos eleitores de formular opinião sobre uma questão específica; refere-se exatamente às especulações dos eleitores sobre a política (Krosnick e Milburn, 1990; Delli Carpini e Keeter, 1996). Embora haja uma diferença entre opinionation e informação, aquela depende desta (Delli Carpini e Keeter, 1996). Ter uma opinião é um indicador de percepção política.

Especificamente neste estudo, em razão de como as variáveis de opinionation foram operacionalizadas, opinionation também é um indicador de 
informação, embora não factual. Em todos os ciclos do painel, solicitou-se que os entrevistados posicionassem os candidatos e os partidos políticos em feeling thermometers (termômetros de impressões), que medem a afinidade do eleitor com um candidato ou um partido em uma escala de 0 a 10, e também que indicassem se conheciam a posição dos candidatos em relação a privatização e reforma agrária. Essas variáveis foram recodificadas para diferenciar entre aqueles capazes de dar uma resposta válida para essas perguntas e aqueles que responderam não saber.

Os eleitores que conseguem julgar candidatos e partidos por meio dos termômetros e que admitem conhecer algo sobre as posições desses candidatos presumivelmente são mais bem informados sobre política que os demais. Entretanto, visto que as posições dos candidatos sobre determinados temas podem mudar com o tempo e que algumas vezes elas não são bem definidas, conhecer as preferências dos candidatos é uma questão de especulação, e não de informação concreta e factual. Ainda assim, as opiniões são baseadas em um mínimo de percepção do sistema político e de seus principais protagonistas ${ }^{11}$.

Quatro índices de opinionation foram operacionalizados: a colocação dada ao candidato nos termômetros de impressão (alpha $=0,81$ ), a colocação atribuída ao partido nesses termômetros (alpha $=0,90$ ); a opinião sobre a posição dos candidatos à presidência em relação à reforma agrária (Opinião - Reforma Agrária; alpha =0,88); e a opinião sobre a posição dos candidatos à presidência quanto à privatização (Opinião Privatização; alpha $=0,89$ ).

\section{O IMPACTO DA INFORMAÇÃO E DA OPINIÃO (OPINIONATION) NO COMPORTAMENTO POLÍTICO}

A quantidade e o tipo de informação que os eleitores precisam para escolher os candidatos e para votar depende de verificação empírica, especialmente na América Latina, onde, como observei anteriormente, há poucos estudos sobre o impacto da informação nas eleições. De fato, como e qual informação afeta as escolhas eleitorais varia conforme o arcabouço institucional (Lupia e McCubbins, 1998; Shugart, Valdini e Suominen, 2005). Assim, antes de concentrar-se nas lacunas de informação, é preciso verificar que tipo de informação é relevante para as escolhas políticas no Brasil. 
A Tabela 2 apresenta os resultados de uma análise multivariada do impacto da informação e da opinião formada no comparecimento às urnas e em votar para candidatos do mesmo partido para distintos cargos em uma mesma eleição (straight-ticket voting). O voto é obrigatório no Brasil; entretanto, pouco se exige para justificar a abstenção ${ }^{12}$. A variável de comparecimento é codificada de 0 a 5 , indicando o número de cargos para os quais o eleitor escolheu um candidato $^{13}$. Dez por cento dos eleitores em ambas as cidades não votaram para nenhum cargo em 2002 e em torno de $40 \%$ votaram para todos os cargos. A hipótese é que os eleitores mais instruídos e com opinião formada (opinionated) têm maior probabilidade de comparecer e votar.

O voto em candidatos do mesmo partido (straight-ticket voting) é operacionalizado como uma variável binária (dummy), indicando se todos os candidatos em que o entrevistado votou pertenciam a um mesmo partido nas eleições para presidente e deputado federal. Votar dessa forma é uma indicação de voto partidário (Mainwaring e Scully, 1995), e pode ser visto como uma forma mais sofisticada de votar, que leva em consideração mais fortemente as questões nacionais e as questões partidárias do que as da esfera local. Trinta por cento dos eleitores em Caxias do Sul e $24 \%$ em Juiz de Fora votaram em candidatos de um mesmo partido nas eleições de 2002. Esse percentual é muito mais baixo do que nos Estados Unidos, onde 70\% dos eleitores o fazem (Lewis-Beck e Nadeau, 2004), o que indica que os partidos políticos no Brasil ainda não moldam a escolha eleitoral com tanta eficácia quanto seus congêneres em outros países (Mainwaring e Scully, 1995). Também é possível especular que os eleitores com opinião mais bem formada e mais bem informados votariam de acordo com o partido.

Além disso, o modelo controla vários fatores políticos e diferenças na participação causadas por gênero, raça e renda ${ }^{14}$. Gênero é uma variável dummy em que os homens recebem o valor 1 e as mulheres, o valor 0 , padrão adotado na maior parte das análises sobre gênero e informação política. Raça também é uma dummy, em que os afro-brasileiros recebem o valor 1. Cabe aqui mencionar que a definição da raça no Brasil é uma tarefa complicada. A classificação racial do indivíduo é geralmente baseada em características físicas, na maioria dos estudos estabelecidas por autodeclaração, que são então recodificadas como dummies brancos/não-brancos. 
A definição da variável adotada aqui é distinta. Ela separa indivíduos que se classificam como cor de pele preta dos demais, incluindo os que se classificam como morenos. Como essa classificação é distinta da tradicionalmente feita, cabe uma explicação. Na essência da justificativa está a idéia de que os afro-descendentes brasileiros, que se classificam com cor de pele preta, têm condição social e econômica muito distinta de mulatos-morenos para serem colocados em uma mesma categoria.

Concordo com essa abordagem, inicialmente desenvolvida por Edward Telles (2004), ao afirmar que, quando pretos e mulatos são colocados na mesma categoria, o efeito da raça é atenuado. Contudo, a abordagem proposta aqui diferencia-se da feita por Telles (idem) por reunir mulatos e morenos a outras categorias, junto com brancos. Isso porque os dados obtidos indicam que há diferenças mais marcantes entre negros e mulatos-morenos do que entre mulatos-morenos e brancos. Por exemplo, na amostra pesquisada, apenas $4 \%$ dos entrevistados que se consideram negros estão entre os $10 \%$ mais ricos. Por outro lado, ao combinar negros e morenos em uma mesma categoria, como fazem os que diferenciam brancos de não-brancos, o número dessa categoria nos $10 \%$ mais ricos sobe para $44 \%$. Portanto, fica claro que, no que tange renda, mulatos e morenos, de um lado, e brancos, de outro, estão quase que igualmente representados nos $10 \%$ mais ricos. Assim sendo, ao distinguir os entrevistados que se classificam como cor de pele preta dos demais, é possível captar de forma mais precisa o impacto da raça. Os que certamente correm o maior risco de enfrentar dificuldades em razão da cor da pele são aqueles que se auto-reconhecem como negros, visto que são eles que sofreram mais o castigo da exclusão no Brasil. Distinguir, portanto, os negros auto-identificados dos mulatos e dos brancos pode captar com mais clareza as diferenças que ficam invisíveis quando os mulatos e os negros são colocados na mesma categoria. É por isso que a variável raça recebe o valor 1 para aqueles que se autodeclaram negros e 0 para todos os outros.

Aqui, também, a variável raça é baseada na auto-identificação dos eleitores, usando as categorias de cor de pele tradicionais presentes no censo brasileiro: negro, branco e pardo - as opções de maior predominância, e amarelo (asiáticos) e indígena (vermelhos). A distribuição dessa variável muda de acordo com a cidade. Caxias do Sul tem uma maioria de brancos (76\%), 15\% se dizem pardos e 5\%, negros. Em Juiz de Fora, a distribuição por raça se assemelha mais ao padrão brasileiro, 
com $55 \%$ se auto-intitulando brancos, $25 \%$ afirmando serem pardos, e $14 \%$, negros.

Os entrevistadores também tiveram que classificar os entrevistados de acordo com sua $\operatorname{cor}^{15}$. Os resultados são praticamente idênticos, com um pequeno aumento de brancos (80\% em Caxias do Sul e $59 \%$ em Juiz de Fora), sem afetar o número de pardos e negros. Eleitores classificados como amarelos (origem oriental) e indígenas foram muito poucos; na autodeclaração de cor, atingem cerca de $2 \%$ cada, em cada cidade, e praticamente desaparecem quando os entrevistadores classificam os entrevistados. Assim, a atribuição de traços raciais não varia enormemente da autodeclaração para as avaliações externas. Os percentuais de pardos e negros na população não são afetados.

Finalmente, a situação econômica do eleitor foi medida de duas formas. A primeira utiliza indicações em termos individuais, baseadas na renda familiar. A variável foi recodificada em uma dummy para diferenciar o décimo percentil superior do resto da população, visando verificar se a parcela mais rica da população é mais bem informada que o resto. A idéia é que o impacto da renda no indivíduo é não-linear, e as principais diferenças são entre os mais ricos e o resto da população. Além disso, a discussão de Tilly (1998) sobre as desigualdades está fortemente ancorada na idéia de categorias exclusivas, que impõem barreiras à mobilidade, em lugar de categorias fluidas. A renda mensurada dicotomicamente reflete mais claramente os aspectos duradouros da desigualdade de classes do que medida como uma variável contínua. Assim, a decisão de codificar essa variável de maneira diferente é justificável em termos metodológicos e teóricos ${ }^{16}$. A renda também foi medida ao nível do bairro, como a renda média do bairro, para assim captar as características dos ambientes em que estão inseridos os eleitores. Essa estratégia dual permite uma avaliação mais completa do impacto do status econômico na aquisição de informação e na participação política.

Voto de classe, definido pela renda, é uma variável explicativa bastante tradicional nos modelos de votação das eleições latino-americanas (Przeworksi e Soares, 1971; Reis e Barboza Filho, 1978; Lamounier, 1975; 1978; 1980; Cew, 1978; Singer, 1999; Carreirão e Barbetta, 2004). Há evidências, a favor e contra, de que essas variáveis desempenham um papel significativo na escolha partidária. Nos primeiros estudos durante a transição para a democracia no Brasil e no Chile, há algumas 
indicações de que a escolha eleitoral refletia diferenças de classes. Estudos mais recentes não tiveram tanto sucesso, faltando-lhes prova que corroborasse essa conclusão. Todavia, nenhum dos estudos sobre desigualdade no acesso à participação política, escolha e informação concentrou-se nessa variável. Esta é uma lacuna que a pesquisa busca suprir.

A Tabela 2 confirma parcialmente as expectativas em relação ao impacto da informação. A informação factual sobre política, indicada pelas variáveis Conhece os Nomes dos Candidatos e a Informação sobre Deputados Federais, tem efeito decisivo, positivo, no comparecimento e no voto em partidos. Portanto, a informação específica sobre as eleições é um forte determinante do comportamento político concreto. Informação geral e opinião formada não são tão importantes quanto informações factuais e específicas. A informação geral não tem nenhum efeito nas escolhas eleitorais, o que confirma que os eleitores não precisam ter conhecimento enciclopédico sobre política para tomar decisões. Além disso, a única variável de opinionation que importa é a capacidade do eleitor de posicionar os candidatos à presidência em termômetros de impressão, que afeta apenas o comparecimento. Assim, nas eleições brasileiras, estar informado dos aspectos específicos da campanha aumenta a probabilidade dos eleitores de depositar um voto partidário.

Renda e gênero também condicionam a participação política. Eleitores do sexo feminino com o mesmo grau de informação que os do sexo masculino têm maior probabilidade de comparecer e de depositar votos em candidatos do mesmo partido (straight-ticket voting). Em outras palavras, um mínimo de informação faz grande diferença para mulheres. Entretanto, quando a variável gênero é inserida em uma regressão bivariada simples de comparecimento e straight-ticket voting, a diferença ou favorece os homens ou não é estatisticamente significativa. Em outras palavras, quando o grau de informação não é levado em consideração, os homens têm maior probabilidade de participar. Isso é mais uma prova de que, além de ter um impacto direto no ativismo político, a informação é também uma variável interveniente fundamental, que afeta a disposição das mulheres em votar. Por outro lado, quando homens e mulheres estão em pé de igualdade em relação à informação política, as diferenças na participação não mais favorecem os homens. Esse é um forte indicador de que mais informação leva a uma redução no hiato participativo entre homens e mulheres. 
Também a renda no bairro exerce um impacto positivo em ambas essas variáveis. Indivíduos em bairros mais ricos têm maior probabilidade tanto de comparecer às urnas, quanto de votar segundo a linha partidária. O impacto da raça não é estatisticamente significativo em nenhuma das cidades, mas o coeficiente é substantivamente alto em Caxias do Sul. Os afro-brasileiros têm maior probabilidade de comparecer que outros eleitores, mantidos constantes os níveis informacionais.

Tabela 2

Coeficientes de Máxima Verossimilhança para o Impacto de Informação e Opinionation em Comparecimento às Urnas e Straight-Ticket Voting Brasil: $2002^{17}$

\begin{tabular}{l|c|c|c|c}
\hline Variáveis & $\begin{array}{c}\text { Compareci- } \\
\text { mento Caxi- } \\
\text { as do Sul }\end{array}$ & $\begin{array}{c}\text { Compareci- } \\
\text { mento Juiz } \\
\text { de Fora }\end{array}$ & $\begin{array}{c}\text { Straight- } \\
\text { Ticket Voting } \\
\text { Caxias do Sul }\end{array}$ & $\begin{array}{c}\text { Straight- } \\
\text { Ticket Voting } \\
\text { Juiz de Fora }\end{array}$ \\
\hline Informação & $0,14^{* *}$ & $0,09^{* * *}$ & $0,16^{* * *}$ & $0,04^{* * *}$ \\
Conhece os Nomes dos Candidatos & $0,64^{* * *}$ & $0,66^{* * *}$ & $1,02^{* * *}$ & $0,78^{* * *}$ \\
Informação sobre Deputados Federais & 0,08 & $-0,05$ & 0,19 & 0,05 \\
Informação Generalizada & 0,02 & 0,03 & 0,02 & 0,03 \\
\hline Opinionation & $-0,02$ & 0,04 & $-0,05$ & $-0,07$ \\
Opinião - Privatização & $0,19^{* * *}$ & $0,19^{* *}$ & 0,04 & $-0,04$ \\
Opinião - Reforma Agrária & 0,02 & $-0,02$ & 0,02 & $-0,01$ \\
Termômetros - Candidatos & & & & \\
Termômetros - Partidos & $-0,17^{* *}$ & $-0,23^{* * *}$ & $-0,23^{*}$ & $-0,03$ \\
\hline Desigualdade & 0,21 & 0,05 & 0,09 & $-0,00$ \\
Homem & 0,06 & $-0,15^{*}$ & $0,26^{* * *}$ & 0,03 \\
Afro-Brasileiro & $0,01^{*}$ & $0,01^{* *}$ & $0,01^{* *}$ & $0,01^{* *}$ \\
\hline 10\% Mais Ricos & $0,41^{* * *}$ & $0,45^{* * *}$ & $0,28^{* * *}$ & $0,21^{* * *}$ \\
Renda Média do Bairro & 22 & 22 & 22 & 22 \\
\hline Redução Proporcional do Erro & 2.490 & 2.524 & 2.490 & 2.524 \\
Número de Estratos & & & & \\
Número de Observações & 22 & & \\
\hline
\end{tabular}

Fonte: Pesquisa Eleitoral em Duas Cidades Brasileiras, coordenada por B. Ames, A. Baker e L. Rennó, Universidade de Pittsburgh/National Science Foundation, 2002.

Obs.: * sign. a 0,$05 ;{ }^{* *}$ sign. a 0,$01 ;{ }^{* *}$ sign. a 0,001 .

A conclusão mais importante aqui, porém, é que eleitores mais bem informados se comportam de maneira diferente de outros menos informados. A informação é importante. Também há um hiato de gênero na participação, favorável às mulheres, quando a informação é mantida 
constante, o que indica que mulheres com o mesmo grau de informação que homens têm maior probabilidade de participar, uma conclusão que contraria a maioria dos estudos sobre mulheres e participação. Dado que a informação política é essencial ao ativismo político em geral e ao estímulo à participação das mulheres nas eleições, a próxima pergunta é: há diferenças na distribuição da informação política por gênero, raça e classe?

\section{DESIGUALDADE E AQUISIÇÃO DE INFORMAÇÃO}

A hipótese central deste estudo é que existem vieses informacionais causados por gênero, raça e status econômico. Se existem hiatos informacionais no Brasil, essas variáveis terão um impacto estatisticamente significativo nas duas variáveis dependentes analisadas: conhecimento dos nomes dos candidatos concorrendo a diferentes cargos e informação sobre os partidos e se o candidato a deputado federal votado está concorrendo a seu primeiro mandato ou à reeleição. Essa abordagem verifica se as fontes essenciais da desigualdade que afetam a distribuição de vários recursos no Brasil são transferidas para o âmbito político. Mais especificamente, a primeira hipótese é que os grupos que foram historicamente marginalizados na sociedade brasileira, mulheres, negros e pobres, terão acesso limitado à informação de campanha.

A primeira hipótese é testada dentro de um modelo mais amplo de aquisição de informação. O modelo leva em consideração que a informação é obtida em conseqüência da conjunção de oportunidade, motivação e capacidade (Luskin, Fiskin e Jowell, 2002).

A oportunidade refere-se às características ambientais que facilitam a aquisição de informação. As campanhas eleitorais são geralmente vistas como amplificadores dos ambientes de informação política em que estão inseridos os eleitores. Uma segunda hipótese é, então, que a aquisição de informação é facilitada pela campanha eleitoral, reduzindo o custo da informação e tornando sua distribuição mais eqüitativa ${ }^{18}$. Portanto, a segunda hipótese é que o hiato informacional causado por raça, classee gênero deve diminuir no decorrer da campanha eleitoral.

Para testar essa hipótese, um indicador da passagem do tempo foi incluído no modelo. Essa variável indica a participação em cada um dos três ciclos de entrevistas no estudo de painel. Um coeficiente positivo para essa variável na análise multivariada indica que os eleitores acumulam informação durante a campanha eleitoral. A variável tempo foi 
recodificada, de forma que o primeiro ciclo recebeu valor 0 e os ciclos subseqüentes, valores 1 e 2 . O modelo interage com raça, gênero e renda para verificar se o impacto destas variáveis muda no tempo. Ao codificar o primeiro ciclo como 0 , a variável de principal efeito para raça, renda e gênero indica o impacto dessas variáveis no primeiro ciclo de entrevistas, a medida de referência para os níveis de informação. O coeficiente para os termos de interação entre a variável tempo, e raça, renda e gênero indica a mudança no impacto dessas variáveis nos ciclos subseqüentes ${ }^{19}$. Destarte, a análise permite avaliar o viés de raça, gênero e renda na informação no começo da campanha e como este viés é atenuado ou aumentado pela campanha eleitoral. Utiliza-se um modelo de curva de crescimento para avaliar vieses no ganho de informação (Singer, 1998).

O modelo é também testado separadamente para cada cidade, de forma a verificar se as distinções entre os diferentes ambientes afetam o ganho de informação. A teoria nos leva a crer que ambientes menos complexos devem facilitar o acesso à informação (Lupia e McCubbins, 1998; Sniderman, 2000; Rahn, 1993; Lau e Redlawsk, 2001). A complexidade eleitoral está geralmente associada ao número de protagonistas políticos no sistema e à visibilidade de suas mensagens, assim, ambientes mais simples, com menos atores com reconhecida reputação, facilitam o ganho de informação. Dessa forma, Caxias do Sul pode ser um terreno mais fértil para o aprendizado.

Contudo, também é possível que o ambiente polarizado de Caxias do Sul resulte em divisões de classe mais marcadas, em que eleitores pobres e ricos não têm interesse em conhecer candidatos e partidos que não os seus próprios. Além disso, o ambiente menos polarizado de Juiz de Fora pode aumentar as oportunidades de deliberação política entre classes, raças e gêneros, resultando em níveis globalmente mais altos de informação. Portanto, a terceira hipótese é que os ambientes irão afetar os hiatos informacionais, mas a direção do impacto não éclaramente especificada pelas teorias existentes e precisa ser verificada.

Além dos determinantes ambientais e temporais da aquisição de informação, a motivação e a capacidade em nível individual também afetam o ganho de informação. O modelo inclui vários fatores que podem influenciar a quantidade de informação que os eleitores adquirem. Eleitores mais motivados prestam mais atenção na mídia, participam mais freqüentemente de conversas sobre política, assistem ao HGPE e con- 
versam com militantes de partidos e candidatos. É natural supor que eleitores mais motivados serão mais bem informados.

Finalmente, o modelo incorpora os fatores relacionados com a capacidade de aprender, os quais incluem: educação; ter emprego; ser dona de casa; ser estudante; e idade. A orientação política, medida pela identificação com o PT e a inclinação ideológica para a esquerda, também pode afetar o conhecimento de política, e por isso foi incluída no modelo. O modelo também controla a propensão dos entrevistados de fazer suposições. A suposição é tida como fator que influencia principalmente o hiato entre homens e mulheres (Mondak e Anderson, 2004; Frazer e MacDonald, 2003; Hayes, 2001; Kenski e Jamieson, 2000; Verba, Burns e Schlozman, 1997). Há uma controvérsia sobre o fato de que os homens têm maior propensão a conjecturar que as mulheres. Diferentes autores encontraram evidências contraditórias apoiando essa hipótese. Ainda assim, para controlá-la, incluiu-se uma variável que reflete a disposição de correr risco ${ }^{20}$.

\section{DESIGUALDADES DE INFORMAÇÃO NO BRASIL}

A análise a seguir trata do impacto de gênero, raça e classe na informação política. É importante conceber e especificar inteiramente o modelo do ganho de informação, para se ter certeza de que os possíveis hiatos causados por gênero, raça e classe não são de fato atribuíveis a outros fatores. Este é, portanto, um teste mais robusto do que avaliar apenas as diferenças nas médias sem controlar outras fontes de variação na aquisição de informação. Não obstante, discutir o impacto de todos os diferentes fatores que influenciam o conhecimento sobre os candidatos está além do escopo deste artigo. O objetivo é exclusivamente mapear vieses nos graus de informação por raça, gênero e renda com confiabilidade e controlando relações espúrias.

A Tabela 3 trata da informação sobre os nomes dos candidatos, medida no tempo ${ }^{21}$. A primeira parte da tabela apresenta os resultados para as três principais variáveis de desigualdade, quando feita a análise de regressão com o modelo completo de aquisição de informação estimado no tempo. A variável Tempo indica como o nível médio de informação muda ao longo dos três ciclos de entrevistas. Os coeficientes para as variáveis de gênero, raça e classe indicam o tamanho do hiato no primeiro ciclo de entrevistas, antes do início da campanha. Os coeficientes para os termos de interação entre tempo e gênero, raça e classe indicam 
como o hiato do início da campanha muda ao longo do tempo para cada variável ${ }^{22}$.

Em relação às hipóteses um e três, fica claro que há um hiato de gênero que favorece os homens em ambas as cidades. Os níveis de informação dos homens são mais altos que os das mulheres no início da campanha, como indicam os principais efeitos para a variável Homem. Embora mulheres com o mesmo nível de informação que homens tendam a participar mais na política, como foi visto na análise anterior, as mulheres em geral são menos informadas sobre política. Isto ocorre independen-

Tabela 3

Coeficientes de Máxima Verossimilhança para Conhecimento sobre os Nomes de Candidatos

Brasil: 2002

\begin{tabular}{l|c|c}
\hline Variáveis & $\begin{array}{c}\text { Conhece os Nomes de } \\
\text { Candidatos } \\
\text { Caxias do Sul }\end{array}$ & $\begin{array}{c}\text { Conhece os Nomes de } \\
\text { Candidatos } \\
\text { Juiz de Fora }\end{array}$ \\
\hline Constante & $4,11^{* * *}$ & $3,72^{* * *}$ \\
\hline Desigualdade & $0,95^{* * *}$ & $0,84^{* * *}$ \\
Homem & $-0,16$ & $-0,49^{* * *}$ \\
Negro & $0,33^{*}$ & 0,08 \\
10\% Mais Ricos & $0,00^{* *}$ & $0,00^{* * *}$ \\
Renda Média do Bairro & $2,62^{* * *}$ & $2,07^{* * *}$ \\
\hline Tempo & 0,13 & $-0,04$ \\
Homem * Tempo & $-0,47^{*}$ & $-0,15$ \\
Negro * Tempo & 0,18 & 0,02 \\
$10 \%$ Mais Ricos * Tempo & 0,00 & $0,00^{* *}$ \\
Renda Média do Bairro * Tempo & 6.973 & 7.165 \\
\hline Nível 1 N - Variação Temporal & 3.384 & 3.250 \\
Nível 2 N - Variação Individual & 22 & 22 \\
Nível 3 N - Variação entre Bairros & $53^{* *}$ & $48 \%$ \\
Redução Proporcional no Erro & & \\
\hline
\end{tabular}

Fonte: Pesquisa Eleitoral em Duas Cidades Brasileiras, coordenada por B. Ames, A. Baker e L. Rennó, Universidade de Pittsburgh/National Science Foundation, 2002.

Obs.: ${ }^{*}$ sign. a 0,$05 ;{ }^{* *}$ sign. a 0,$01 ;{ }^{* *}$ sign. a 0,001 . 
temente do ambiente em que estejam inseridos os homens e as mulheres. Em ambas as cidades, o hiato de gênero é o mais profundo.

O hiato de raça é maior em Juiz de Fora do que em Caxias do Sul no início da campanha. Isso indica que um ambiente complexo, como o de Juiz de Fora, impõe custos de aprendizado mais altos quando a informação é menos abundante, o que tem suporte nos resultados dos principais efeitos da variável Raça ${ }^{23}$.

A variável no nível individual para renda em Caxias do Sul também indica uma diferença nos graus de informação logo no começo da campanha. Embora a raça não tenha relevância no início da campanha nessa cidade, a renda tem. O 10 percentil superior é mais bem informado quando a informação está menos disponível. Esse resultado é esperado, porque a divisão de classes entre ricos e pobres em Caxias do Sul é bastante forte e profunda, ao passo que em Juiz de Fora não o é. Novamente, o custo da informação no início da campanha pode prejudicar a capacidade dos eleitores de Caxias do Sul de aprender. Isso é acentuado pela forte divisão ideológica entre ricos e pobres, que pode ainda obstruir a distribuição da informação. Em Juiz de Fora, onde essa divisão não é tão forte, as diferenças de classe não são decisivas em termos de seu efeito na informação política. Ricos e pobres não são tão diferentes quando se trata dos níveis de informação política em um ambiente menos dividido ${ }^{24}$.

Contudo, a renda do bairro é um fator que influencia os níveis informacionais, independentemente da cidade, indicando que diferenças na renda, quando medidas como um fator ambiental, afetam a informação. Essa conclusão deve ser ainda mais ressaltada, pois o tamanho da amostra para os bairros, o nível mais alto de análise no Modelo Hierárquico usado em cada cidade, é de apenas 22 casos por cidade. Portanto, atingir significância estatística com um número tão pequeno de casos indica a força do impacto.

A terceira hipótese é que, com o decorrer da campanha eleitoral, cairá o custo da informação e, portanto, diminuirão os hiatos causados por raça, classe e gênero. Em primeiro lugar, o coeficiente positivo e estatisticamente significativo para tempo indica que os eleitores aprendem durante a campanha. Eles também aprendem um pouco mais rapidamente em Caxias do Sul, onde o ambiente é mais simples. Entretanto, os hiatos causados por gênero, raça e renda não parecem mudar enormemente durante a campanha. Tanto em Caxias do Sul quanto em Juiz 
de Fora não há mudanças estatisticamente significativas no coeficiente para a diferença entre homens e mulheres. Também não há mudanças estatisticamente significativas para diferenças entre ricos e pobres medidas em nível individual. As únicas mudanças no impacto dos indicadores de desigualdade são em função de raça em Caxias do Sul, onde os níveis de informação dos afro-brasileiros diminuem durante a campanha, e em função da renda do bairro em Juiz de Fora, onde os eleitores em bairros ricos tornam-se ainda mais bem informados. Portanto, embora a campanha eleitoral aumente os níveis globais de informação dos eleitores, tais aumentos não beneficiam grupos menos privilegiados. A taxa de aprendizado não varia segundo o grupo social e, quando varia, beneficia os grupos já privilegiados.

\section{CONCLUSÕES}

Este artigo testa se as desigualdades baseadas em raça, gênero e renda transferem-se para o âmbito político no Brasil. De fato, o artigo confirma que há vieses na distribuição da informação e na participação política. Isso é feito, primeiro, verificando quais são os determinantes da participação política e testando em que medida a informação política afeta o comparecimento e o voto vertical, em lugar de simplesmente supor que tem importância. Uma vez determinado que apenas a informação de campanha factual e específica afeta o comparecimento e o voto em candidatos do mesmo partido para cargos distintos (straight-ticket voting), o artigo trata de modelar a distribuição da informação sobre os nomes dos candidatos e sobre as características dos deputados federais, usando um modelo amplo de aquisição de informação durante a campanha. A principal preocupação, porém, é verificar se hiatos na informação causados por raça, gênero e status econômico afetam a distribuição da informação, mesmo quando se está controlando outras possíveis explicações para a variação na informação política.

Uma primeira conclusão é que os eleitores que são mais bem informados sobre os protagonistas do processo eleitoral têm maior propensão a comparecer e a votar em candidatos de um mesmo partido. Eleitores que têm informação generalizada ou opinião formada não têm maior probabilidade de participar. Portanto, no caso de comparecimento e voto vertical, a informação específica de campanha tem mais importância que qualquer outro tipo de informação. Segundo, existe um hiato de gênero e renda de bairro consistente na participação política, quando os níveis informacionais são mantidos constantes. Mulheres 
com o mesmo nível de informação que homens têm maior probabilidade de participar da política, assim como eleitores que vivem em bairros ricos, com o mesmo nível informacional que os que vivem em bairros pobres. A diferença, porém, entre homens e mulheres, sem considerar os níveis de informação, favorece os homens. Assim, informação é um fator-chave que influencia o comportamento concreto de todos os grupos, mas afeta especificamente as diferenças na participação entre homens e mulheres. A informação aumenta a participação das mulheres.

Contudo, há um problema. A terceira principal conclusão deste estudo é que os homens são consistentemente mais bem informados sobre os candidatos a cargos políticos do que as mulheres, e isso se mantém constante durante toda a campanha. Ainda assim, o hiato de gênero na informação política permanece, mesmo quando se controlam as várias outras potenciais explicações para a existência do hiato.

O único outro impacto consistente na aquisição de informação, independentemente do ambiente e do tempo decorrido, é o da renda medida no bairro. Assim, parece que a renda média do bairro distingue com mais clareza os que possuem e os despossuídos, quando se trata de informação política e participação, do que as medidas do nível individual de renda. $\mathrm{O}$ ambiente do bairro homogeneíza as diferenças individuais e condições de acesso à informação mais claramente do que a variância no nível individual.

Finalmente, parece que as características ambientais afetam o impacto das desigualdades duradouras. Em ambientes mais complexos, os custos de informação de campanha são altos durante toda ela. Conseqüentemente, é difícil para aqueles cujos custos da informação são especialmente altos alcançarem os níveis de informação de grupos mais privilegiados.

Quais são as implicações destas conclusões para a política brasileira? Primeiro, as conclusões indicam que os eleitores aprendem, sim, durante a campanha, mas que esse aprendizado não atenua alguns dos custos do ganho de informação para grupos específicos. Pior, os grupos que têm acesso reduzido à informação são os mesmos que foram historicamente excluídos do acesso a diversos outros recursos no Brasil. No final, o hiato informacional beneficia ricos, brancos e homens, especialmente em ambientes políticos mais complexos. Portanto, as desigualdades parecem permear as diferentes esferas da sociedade brasileira, o que está no cerne de sua resiliência no tempo no Brasil. 
O que deve ser feito a respeito desses hiatos é necessariamente a próxima pergunta. $\mathrm{O}$ fato de que as mulheres com os mesmos níveis de informação que os homens serem mais ativas é muito interessante e pode ser a essência para entender por que as mulheres no Brasil tiveram tanto êxito em melhorar seu acesso a recursos nos últimos anos. Por exemplo, existem cotas no processo de escolha de candidatos à Câmara dos Deputados. Porém, esse ganho, embora significativo, não se reflete efetivamente em aumento do número de mulheres no Congresso, nem na influência exercida pelas mulheres na tomada de decisões governamentais. Dado que as cotas de indicação de candidatos não garantem as cadeiras, as mulheres ainda são sub-representadas no Congresso. É possível que uma distribuição mais eqüitativa da informação ajude as mulheres a aumentar ainda mais suas conquistas políticas e voz. $\mathrm{O}$ mesmo, obviamente, pode-se dizer em relação aos eleitores afro-brasileiros e pobres, que não obtiveram ganhos tão significativos quanto as mulheres em sua busca por eqüidade.

Estudos futuros devem contemplar algumas das questões que não puderam ser tratadas aqui. Primeiro, pode-se explorar como diferentes tipos de questões podem ser dominados por diferentes grupos. Por exemplo, as mulheres estão mais preocupadas com questões sociais e estas pesam mais no seu processo de tomada de decisões? Além disso, os eleitores com diferentes características têm maior probabilidade de serem influenciados por líderes locais e círculos de amigos e familiares? Os pobres são alvos de agentes clientelistas que trocam bens materiais por votos (Auyero, 2000; Brusco, Nazareno e Stokes, 2004; Gay, 1994)? Finalmente, quais são os fatores, além da exposição à campanha e das características ambientais, que podem reduzir os hiatos informacionais e participativos? Todas essas perguntas merecem ser exploradas para tentar explicar como elementos perenes de desigualdade afetam a política no Brasil e na América Latina.

Finalmente, a abordagem adotada aqui pode ser facilmente aplicada a outros países, em uma análise comparativa internacional. Os hiatos informacionais e participativos ocorrem em toda a América Latina? Eles certamente existem nos Estados Unidos, como foi extensivamente documentado por Delli Carpini e Keeter (1996). Portanto, é muito provável que os vieses na voz e na informação políticas sejam um traço de to- 


\section{dos os países nos quais a desigualdade desempenha um papel signifi- cativo na alocação de recursos.}

(Recebido para publicação em fevereiro de 2007)

(Versão definitiva em outubro de 2007)

\section{NOTAS}

1. Para discussões sobre discriminação de gênero, raça e renda, veja Skidmore (1993), Lovell (2000; 2000a) e Andrews (1996). Discriminação de renda, de status econômico e de classe econômica serão utilizadas de forma intercambiável neste estudo, referindo-se a questões baseadas nas diferenças salariais entre indivíduos.

2. As desigualdades também podem se acumular de outra maneira: os indivíduos que têm mais de uma característica de um grupo excluído, como, por exemplo, ser negro e pobre, têm dupla ou tripla dificuldade de viver a vida. Ou seja, uma mulher negra e pobre no Brasil, na África do Sul ou nos Estados Unidos começa sua vida em inquestionável desvantagem em comparação com uma mulher branca de classe média. Histórias reais de mulheres brasileiras negras e pobres mostram claramente que não estão em condições de igualdade com outros homens e mulheres e que, na maioria dos casos, estão fadadas a ter uma vida difícil (Patai, 1988). Este tipo de acumulação de desigualdades não será analisado diretamente neste artigo. O principal enfoque aqui está na transmissão das desigualdades entre recursos.

3. Lupia e McCubbins (2000:47-48) definem como "escolha sensata" aquela em que o indivíduo sabe das conseqüências de suas ações.

4. Há várias maneiras de apresentar aos eleitores informações de forma resumida. As mensagens mais comuns são sobre os partidos políticos, os patrocinadores e se o candidato está concorrendo ao seu primeiro mandato ou à reeleição (incumbency status). Todos esses fatores são atalhos que fornecem provas do desempenho de um candidato no passado e de como deverá se posicionar no futuro. Em outras palavras, conhecer o partido político, os patrocinadores e o incumbency status pode ser suficiente para instruir os eleitores, pois estes elementos fornecem indicação das posições de um candidato sobre questões e políticas públicas.

5. Obviamente, aqueles que têm mais do que o mínimo de informações estão sempre em melhores condições. Bartels (1993) argumenta que eleitores mais bem informados agem de maneira diferente dos demais. Além disso, os eleitores bem informados tendem a votar mais moderadamente do que os menos informados (Luskin, Fiskin e Jowell, 2002) e têm menos dúvidas quanto às posições dos candidatos em relação a políticas públicas (Alvarez e Brehm, 2002).

6. Veja uma exceção em Oliveira (1999). 
7. O Jornal Nacional da TV Globo e o Jornal do Bóris do Sistema Brasileiro de Televisão SBT foram codificados de 21 de agosto a 25 de outubro de 2002 por dois distintos codificadores.

8. O termo é uma tradução de opinionation, que indica a disposição de proferir uma opinião sobre um tema político.

9. Essas distinções não são mutuamente excludentes. Um generalista pode também ser um especialista em determinada área.

10. Ver no Anexo a descrição das variáveis.

11. Novamente, faço referência a essas variáveis como indicadores de opiniões porque as posições dos candidatos sobre os temas são, na maioria das vezes, pouco claras e difíceis de identificar, e portanto não há como afirmar se a avaliação do entrevistado está correta ou incorreta.

12. Os eleitores só podem votar nas cidades em que estão registrados; se estiverem fora, devem justificar seu não-comparecimento às urnas. Isso pode ser feito no dia das eleições, enviando uma justificativa por escrito ao tribunal de seu domicílio eleitoral. Os formulários de justificativa de ausência são fornecidos nas seções eleitorais, e o eleitor precisa apenas ir a uma delas e preencher o documento. Os eleitores também podem se justificar após as eleições, indo diretamente ao tribunal eleitoral de seu município de residência e pagando uma multa de valor quase simbólico.

13. O Brasil realiza eleições gerais a cada quatro anos, e os eleitores votam para presidente, governador, senador, deputado federal e deputado estadual. Em 2002, eram dois votos para o Senado Federal. A variável de resultado não inclui os votos para deputado estadual, mas inclui os dois votos para senador, por isso varia de 0 a 5 . Os votos em branco ou nulos são considerados inválidos e codificados como 0 .

14. Os controles incluem variáveis socioeconômicas, participação em organizações da sociedade civil, identificação com o PT, ideologia, atenção da mídia, propensão a participar de conversas políticas e o número de debatedores políticos. De todos esses, a influência mais consistente em votar em candidatos do mesmo partido (straightticket voting) e no comparecimento é a identificação com o PT, que aumenta a probabilidade de ambos. As outras variáveis apresentam resultados inconsistentes.

15. Para evitar contaminação da classificação, os entrevistadores foram instruídos a classificar o entrevistado silenciosamente, antes de pedir-lhe para se auto-identificar.

16. A renda foi imputada em aproximadamente 100 casos. As variáveis usadas para a imputação foram raça, gênero, escolaridade, se está ou não empregado, e idade. A variável foi então logaritmizada para normalizar a distribuição.

17. Dado que a análise contém medidas em diferentes níveis, um Modelo Hierárquico é mais apropriado. Todos os modelos foram estimados usando-se HLM 5.0.

18. Fiorina (1990) e Popkin (1991) afirmam que as campanhas eleitorais reduzem o custo da informação.

19. Ver em Jaccard e Turrisi (2003) uma discussão dos termos da interação na análise de regressão.

20. Essa variável foi uma inovação introduzida em estudos das eleições mexicanas, especialmente por Morgenstern e Zechmeister (2001). A premissa é que a suposição é mais provável entre os entrevistados que aceitam riscos do que entre os que são aves- 
sos a eles. Para operacionalizar essa aversão ao risco, os entrevistados tiveram que escolher entre dois ditados populares muito conhecidos no Brasil. A primeira opção era "mais vale um pássaro na mão do que dois voando". O segundo era "quem não arrisca não petisca". Aqueles que escolheram a segunda opção foram considerados indivíduos que aceitam riscos e, assim, mais propensos a conjecturar e a responder às perguntas corretamente. De fato, confirmando estudos anteriores, as mulheres têm maior probabilidade de ser avessas ao risco. Daqueles que aceitam riscos, 57\% são homens e $42 \%$ são mulheres. Um último controle refere-se a aspectos do projeto da pesquisa. Devido ao fato de que o condicionamento de painel pode afetar as mensurações de um mesmo indivíduo no tempo (Bartels, 1999) e porque as variáveis de informação são particularmente sensíveis ao condicionamento do painel (Brehm, 1993), novas seções cruzadas foram entrevistadas nos ciclos 2 e 3, para controlar as diferenças entre os entrevistados do painel e o resto da população. Dummies foram acrescentadas ao modelo para refletir os entrevistados substituídos nos ciclos 2 e 3 .

21. Os dados incluem mensurações nos diferentes níveis de análise. Há medições para os indivíduos no tempo, entre indivíduos (que é o mesmo que entre bairros) e entre bairros. Portanto, a técnica de estimação mais apropriada é um Modelo Hierárquico, que estima tanto os efeitos fixos como os aleatórios. Dado que todas as variáveis são contagens, mas não muito assimétricas e com várias categorias, eu modelo sua distribuição usando uma função de link de identidade (identity link function). Também testei os mesmos modelos usando uma função de link de Poisson (Poisson linkfunction), e os resultados não variam. Dado que a primeira função facilita a interpretação dos resultados por não alterar a unidade de medida da variável dependente, optei por apresentar esses coeficientes em lugar dos de Poisson. A equação pode ser encontrada no Anexo. Para leituras sobre modelos hierárquicos, veja Raudenbush e Bryk (2003) e Verbeke e Molenberghs (2000).

22. O modelo testado, como foi dito, inclui várias outras explicações para a aquisição de informação com base no modelo proposto. Dado o meu objetivo imediato de focar na desigualdade baseada em raça, gênero e renda, as outras variáveis no modelo não serão discutidas. Entretanto, é preciso ficar claro que o modelo controla os níveis educacionais, a ocupação, as variáveis de participação política e várias outras possíveis explicações para a aquisição de informação.

23. Apenas para recapitular, os "principais efeitos" indicam o efeito de ser negro na informação sobre os candidatos no primeiro ciclo de entrevistas, ou seja, no momento anterior à campanha eleitoral.

24. Um dos revisores insistiu que deveria ser feito um teste usando a classificação tricotômica de raça e o log da renda. Esta possibilidade está aberta para pesquisadores que se interessem em fazer este teste. Os dados estão disponíveis aos interessados, basta consultar o autor. 


\section{REFERÊNCIAS BIBLIOGRÁFICAS}

ALVAREZ, Michael e BREHM, John. (2002), Hard Choices, Easy Answers: Values, Information and American Public Opinion. Princeton, Princeton University Press.

ANDREWS, George Reid. (1996), “Brazilian Racial Democracy, 1900-90: An American Counterpoint". Journal of Contemporary History, vol. 31, no 3, pp. 483-507.

AUYERO, Javier. (2000), "The Logic of Clientelism in Argentina: An Ethnographic Account". Latin American Research Review, vol. 35, no 3, pp. 55-81.

BARTELS, Larry M. (1988), Presidential Primaries and the Dynamics of Public Choice. Princeton, Princeton University Press.

. (1993), "Messages Received: The Political Impact of Media Exposure". American Political Science Review, no 30, pp. 709-723.

(1999), "Panel Effects in the American National Election Studies". Political Analysis, vol. 8, no 1, pp. 1-19.

. (2005), "Homer Gets a Tax Cut: Inequality and Public Policy in the American Mind". Perspectives on Politics, vol. 3, no 1, pp. 15-32.

BOLLEN, K. e JACKMAN, R. (1985), "Political Democracy and the Size Distribution of Income". American Sociological Review, vol. 50, no 4, pp. 438-457.

BREHM, John. (1993), The Phantom Respondents. Ann Arbor, University of Michigan Press.

BRUSCO, Valeria, NAZARENO, Marcelo e STOKES, Susan. (2004), "Vote Buying in Argentina". Latin American Research Review, vol. 39, no 2, pp. 66-88.

CAMPBELL, Angus, CONVERSE, Phillip, MILLER, Warren e STOKES, Donald. (1960), The American Voter. New York, Wiley Publishing.

CARREIRÃO, Yan e BARBETTA, Pedro Alberto. (2004), “A Eleição Presidencial de 2002: A Decisão de Voto na Região da Grande São Paulo". Revista Brasileira de Ciências Sociais, vol. 19, no 56 , pp. 56-79.

CEW, Judson de. (1978), “A Decisão Eleitoral em Caxias do Sul”, in F. W. Reis (ed.), Os Partidos e o Regime: A Lógica do Processo Eleitoral Brasileiro. São Paulo, Símbolo, pp. 184-212.

DELLI CARPINI, Michael X. e KEETER, Scott. (1996), What Americans Know About Politics and Why It Matters. New Haven, Yale University Press.

FIORINA, Morris. (1990), "Information and Rationality in Elections", in J. Ferejohn e J. Kuklinski (eds.), Information and Democratic Processes. Chicago, University of Illinois Press.

FRAZER, Elizabeth e MACDONALD, Kenneth. (2003), "Sex Difference in Political Knowledge in Britain". Political Studies, vol. 51, no 1, pp. 67-83.

GAY, Robert. (1994), Popular Organization and Democracy in Rio de Janeiro: A Tale of Two Favelas. Philadelphia, Temple University Press. 
HAYES, Bernadette. (2001), "Gender, Scientific Knowledge, and Attitudes toward the Environment: A Cross-National Analysis". Political Research Quarterly, vol. 54, no 3, pp. 657-671.

HOFFMAN, Kelly e CENTENO, Miguel Angel. (2003), “The Lopsided Continent: Inequality in Latin America". Annual Review of Sociology, vol. 29, pp. 363-390.

HUCKFELDT, Robert e SPRAGUE, John. (1995), Citizens, Politics, and Social Communication. Cambridge, Cambridge University Press.

JACCARD, James e TURRISI, Robert. (2003), Interaction Effects in Multiple Regression. Thousand Oaks, Sage.

KENSKI, Kate e JAMIESON, Kathleen. (2000), “The Gender Gap in Political Knowledge: Are Women Less Knowledgeable than Men about Politics?", in K. Jamieson (ed.), Everything You Think You Know About Politics... And Why You're Wrong. New York, Basic Books, pp. 83-89.

KORZENIEWICZ, Roberto P. e SMITH, William. (2000), "Poverty, Inequality and Growth in Latin America: Searching for the High Road to Globalization". Latin American Research Review, vol. 35, no 3, pp. 7-54.

KROSNICK, Jon e MILBURN, Michael. (1990), "Psychological Determinants of Political Opinionation". Social Cognition, no 8, pp. 49-72.

LAMOUNIER, Bolivar. (1975), “Comportamento Eleitoral em São Paulo: Passado e Presente", in B. Lamounier e F. H. Cardoso (orgs.), Os Partidos e as Eleições no Brasil. Rio de Janeiro, Paz e Terra, pp. 15-44.

. (1978), "Presidente Prudente: OCrescimento da Oposição num Reduto Arenista", in F. W. Reis (org.), Os Partidos e o Regime: A Lógica do Processo Eleitoral Brasileiro. São Paulo, Símbolo, pp. 1-90.

. (1980), “O Voto em São Paulo, 1970-1978”, in B. Lamounier (org.), Voto da Desconfiança: Eleições e Mudança Política no Brasil, 1970-1979. São Paulo, Vozes, pp. 15-80.

LAU, Richard e REDLAWSK, David. (2001), “Advantages and Disadvantages of Cognitive Heuristics in Political Decision Making". American Journal of Political Science, vol. 45, no 4, pp. 951-971.

LAZARSFELD, Paul, BERELSON, Bernard e GAUDET, Hazel. (1944), The People's Choice. New York, Columbia University Press.

LEWIS-BECK, Michael e NADEAU, Richard. (2004), "Split-Ticket Voting: The Effects of Cognitive Madisonianism". Journal of Politics, vol. 66, no 1, pp. 97-112.

LIMA, Venicio A. de. (1993), "Brazilian Television in the 1989 Presidential Campaign: Constructing a President", in T. Skidmore (ed.), Television, Politics, and the Transition to Democracy in Latin America. Washington, The Woodrow Wilson Center Press, pp. 97-117.

LOVELL, Peggy. (2000), “Race, Gender and Regional Labor Market Inequalities in Brazil". Review of Social Economy, vol. LVIII, no 3, pp. 277-293.

. (2000a), "Gender, Race and the Struggle for Social Justice in Brazil". Latin American Perspectives, vol. 115, no 27, pp. 85-113. 
LUPIA, Arthur e MCCUBBINS, Mathew. (1998), The Democratic Dilemma: Can Citizens Learn What They Need to Know? Cambridge, Cambridge University Press.

(2000), "The Institutional Foundations of Political Competence: How Citizens Learn What They Need to Know", in A. Lupia, M. McCubbins e S. Popkin (eds.), Elements of Reason: Cognition, Choice, and the Bounds of Rationality. Cambridge, Cambridge University Press.

LUSKIN, Robert. (2002), "From Denial to Extenuation (and Finally Beyond): Political Sophistication and Citizen Performance", in J. Kuklinski (ed.), Thinking about Political Psychology. Cambridge, Cambridge University Press.

FISKIN, James e JOWELL, Roger. (2002), “Considered Opinions: Deliberative Polling in Britain". British Journal of Political Science, vol. 32, pp. 455-487.

MAINWARING, Scott e SCULLY, Timothy. (1995), Building Democratic Institutions: Party Systems in Latin America. Stanford, Stanford University Press.

MIGUEL, Luis Felipe. (1999), "Mídia e Eleições: A Campanha de 1998 na Rede Globo". DADOS, vol. 42, no 2, pp. 253-276.

MONDAK, Jeffery e ANDERSON, Mary. (2004), “The Knowledge Gap: A Reexamination of Gender-Based Differences in Political Knowledge". Journal of Politics, vol. 66, no 2, pp. 492-512.

MORGENSTERN, Scott e ZECHMEISTER, Elizabeth. (2001), "Better the Devil You Know than the Saint You Don't: Risk Propensity and Vote Choice in Mexico". Journal of Politics, vol. 63, no 1, pp. 93-119.

MULLER, Edward. (1988), “Democracy, Economic Development, and Income Inequality," American Sociological Review, vol. 53, no 1, pp.50-68.

NIEMI, Richard e WEISBERG, Herbert (eds.). (2001), Controversies in Voting Behavior. Washington, CQ Press.

OLIVEIRA, Clovis L. P. (1999), “Struggling for a Place: Race, Gender and Class in Political Elections in Brazil", in R. Reichmann (ed.), Race in Contemporary Brazil: From Indiference to Inequality. University Park, The Pennsylvania State University Press.

PATAI, Daphne. (1988), Brazilian Women Speak: Contemporary Life Stories. New Brunswick, Rutgers University Press.

POPKIN, Samuel. (1991), The Reasoning Voter. Chicago, The University of Chicago Press.

PORTES, Alejandro e HOFFMAN, Kelly. (2003), “Latin American Class Structures: Their Composition and Change during the Neoliberal Era". Latin American Research Review, vol. 38, no 1, pp. 41-82.

PRZEWORSKI, Adam eSOARES, Glaucio. (1971), “Theories in Search of a Curve: AContextual Interpretation of the Left Vote". American Political Science Review, vol. 65, pp. 51-68.

RAHN, Wendy. (1993), "The Role of Partisan Stereotypes in Information Processing about Political Candidates". American Journal of Political Science, vol. 37, no 2, pp. 472-496.

RAUDENBUSH, Stephen e BRYK, Anthony. (2003), Hierarchical Linear Models: Applications and Data Analysis Methods. Newbury Park, Sage. 
REIS, Fabio W. e BARBOZA FILHO, Rubem. (1978), "Classe Social e Opção Partidária: As Eleições de 1976 em Juiz de Fora", in F. W. Reis (ed.), Os Partidos e o Regime: A Lógica do Processo Eleitoral Brasileiro. São Paulo, Símbolo, pp. 213-282.

RENNÓ, L. R. (2006), “O Dilema do Rico: Número de Candidatos, Identificação Partidária e Accountability nas Eleições de 2002 para a Câmara dos Deputados", in G. A. D. Soares e L. Rennó (orgs.), Reforma Política: Lições da História Recente (1a ed.). Rio de Janeiro, Editora FGV, pp. 47-70.

SHUGART, Matthew, VALDINI, Melody e SUOMINEN, Kati. (2005), "Looking for Locals: Voter Information Demands and Personal Vote-Earning Attributes of Legislators under Proportional Representation". American Journal of Political Science, vol. 49, no 2, PP. 437-449.

SINGER, Andre. (1999), Esquerda e Direita no Eleitorado Brasileiro: A Identificação Ideológica nas Disputas Presidenciais de 1989 e 1994. São Paulo, Edusp.

SINGER, Judith. (1998), “Using SAS PROC MIXED to Fit Multilevel Models, Hierarchical Models, and Individual Growth Curve Models". Journal of Educational and Behavioral Statistics, vol. 24, no 4, pp. 323-355.

SKIDMORE, Thomas. (1993), Black into White: Race and Nationality in Brazilian Thought. Durham, Duke University Press.

SNIDERMAN, Paul. (2000), "Taking Sides: A Fixed Choice Theory of Political Reasoning", in A. Lupia, M. McCubbins e S. Popkin (eds.), Elements of Reason: Cognition, Choice, and the Bounds of Rationality. Cambridge, Cambridge University Press.

TELLES, Edward. (2004), Race in Another America: The Significance of Skin Color in Brazil. Princeton, Princeton University Press.

TILLY, Charles. (1998), Durable Inequality. Berkeley, University of California Press.

VERBA, Sidney, BURNS, Nancy e SCHLOZMAN, Kay. (1997), "Knowing and Caring about Politics: Gender and Political Engagement". Journal of Politics, vol. 59, pp. 1.051-1.057.

VERBEKE, Geert e MOLENBERGHS, Geert. (2000), Linear Mixed Models for Longitudinal Data. New York, Springer-Verlag. 


\section{ANEXO \\ Descrição das Variáveis}

\begin{tabular}{|c|c|}
\hline Variáveis & Descrição \\
\hline \multicolumn{2}{|l|}{ Informação Política } \\
\hline $\begin{array}{l}\text { Conhece os Nomes dos Candi- } \\
\text { datos }\end{array}$ & $\begin{array}{l}\text { Índice composto por quatro variáveis que pedem } \\
\text { ao entrevistado que nomeie candidatos a presi- } \\
\text { dente, governador, senador e deputado federal. } \\
\text { Os valores variam de } 0 \text { a } 23 \text {, e é uma contagem } \\
\text { dos nomes ditos corretamente. }\end{array}$ \\
\hline $\begin{array}{l}\text { Informação sobre Deputados } \\
\text { Federais }\end{array}$ & $\begin{array}{l}\text { Índice composto por três variáveis dicotômicas } \\
\text { que indicam se o entrevistado sabe se o candida- } \\
\text { to a deputado federal em que votou se elegeu, se } \\
\text { sabe o nome do partido do candidato a deputado } \\
\text { federal em que votou e se sabia se o candidato a } \\
\text { deputado federal concorria à reeleição ou não. }\end{array}$ \\
\hline Informação Generalizada & $\begin{array}{l}\text { Esta variável é baseada em uma questão feita ao } \\
\text { entrevistador sobre o nível de conhecimento do } \\
\text { entrevistado. A variável foi recodificada em uma } \\
\text { dummy para diferenciar os eleitores que têm mui- } \\
\text { ta ou alguma informação de todos os demais. }\end{array}$ \\
\hline \multicolumn{2}{|l|}{ Opinionation } \\
\hline Opinião - Privatização & $\begin{array}{l}\text { Índice composto por quatro variáveis que indi- } \\
\text { cam se o entrevistado sabe se os quatro princi- } \\
\text { pais candidatos à presidente (Lula, Serra, Ciro, } \\
\text { Garotinho) são fortemente contra, contra, neu- } \\
\text { tros, a favor ou fortemente a favor da privatiza- } \\
\text { ção. Os que não sabiam responder receberam va- } \\
\text { lor 0. Os que ofereceram uma resposta receberam } \\
\text { valor } 1 \text {. As respostas dadas foram tidas como cor- } \\
\text { retas sem qualquer avaliação minha porque as } \\
\text { posturas dos candidatos não eram absolutamente } \\
\text { claras sobre esse tema. Por isso, é também consi- } \\
\text { derada uma questão de opinião. }\end{array}$ \\
\hline Opinião - Reforma Agrária & Mesma lógica da variável anterior. \\
\hline Termômetro - Candidatos & $\begin{array}{l}\text { Índice composto por quatro variáveis indicando } \\
\text { se o entrevistado consegue posicionar os princi- } \\
\text { pais candidatos à presidente (Lula, Serra, Ciro, } \\
\text { Garotinho) em termômetros, feeling thermometers. } \\
\text { Entrevistados que expressaram uma opinião so- } \\
\text { bre os candidatos receberam valor } 1 \text {. Os que não } \\
\text { expressaram uma opinião receberam valor } 0 .\end{array}$ \\
\hline Termômetro - Partidos & $\begin{array}{l}\text { Mesma lógica da variável anterior, só que refe- } \\
\text { rente aos quatro principais partidos do país (PT, } \\
\text { PMDB, PSDB, PFL). }\end{array}$ \\
\hline
\end{tabular}




\section{Indicadores de Desigualdade}

Afro-Brasileiro

Renda

Renda Média Do Bairro

Homem
Resposta a uma pergunta sobre cor da pele.

Quem se classificou como cor da pele preta recebeu valor 1. Os demais foram agrupados em uma categoria única com valor 0 .

Recebe código 1 se o entrevistado se posiciona no $10^{\circ}$ percentil mais alto na distribuição de renda declarada dos entrevistados. A variável é baseada em uma pergunta sobre a renda mensal total da família.

Média da renda familiar medida no nível individual por bairro.

Gênero do entrevistado. Homem recebe valor 1 e mulher valor 0 .

\section{Predisposições Políticas Individuais}

Identificação com o PT

Ideologia - Esquerda

2 = Identificação Forte com o PT; 1 = Identificação Fraca com o PT; 0 = Não se identifica com o PT.

1 = Posiciona-se na categoria Esquerda em uma escala de 5 pontos que vai de Esquerda à Direita; $0=$ Não se posiciona na categoria Esquerda.

\section{Motivações Individuais}

Participação em Associações de Bairro e em Reuniões do Orçamento Participativo

Conversação Política

Atenção à Mídia

Horário Gratuito de Propaganda Eleitoral

\section{Características Individuais}

Recebem valor 1 os entrevistados que participaram de alguma reunião dessas organizações no ano passado.

Índice composto por respostas a itens sobre hábitos de conversar sobre política com amigos, vizinhos, colegas de trabalho e familiares.

Índice composto por respostas a itens sobre freqüência com que assiste a jornais de televisão e lê jornais escritos.

Variável dicotômica indicando se o entrevistado assistiu a algum programa do HGPE.
Escolaridade

Idade
Resposta a um item sobre até que série cursou. Varia de 0, analfabeto, a 15, pós-graduação completa.

Idade do entrevistado baseada em uma questão sobre data de nascimento. Foi acrescido também um valor ao quadrado dessa variável para medir um efeito não-linear da mesma. Teoricamente espera-se que, após certa idade, a capacidade de aprender sobre política diminua. 
Estado Civil

Situação de Emprego

Estudante

Dona de Casa
Recebe valor 1 se o entrevistado for casado, formalmente ou informalmente.

Recebe valor 1 se estiver empregado.

Recebe valor 1 se for estudante.

Recebe valor 1 se for dona de casa.

\section{Controles para Desenho de Pesquisa}

Reposições para a Segunda Rodada de Entrevistas

Reposições para a Terceira Rodada de Entrevistas

Tempo
Recebe valor 1 se o entrevistado começou a participar da pesquisa na segunda rodada de entrevistas.

Recebe valor 1 se o entrevistado começou a participar da pesquisa na terceira rodada de entrevistas.

Valor 0 para entrevistas feitas na primeira rodada de entrevistas; valor 1 para entrevistas feitas na segunda rodada de entrevistas; valor 3 para entrevistas feitas na última rodada de entrevistas.

\section{EQUAÇÕES PARA OS DISTINTOS MODELOS}

Equação de dois níveis para comparecimento às urnas e Straight-Ticket Voting

Modelo do Primeiro Nível

$$
\begin{aligned}
& \mathrm{Y}=\mathrm{B} 0+\mathrm{B} 1 *(\text { ESCOLARIDADE })+\mathrm{B} 2 *(\text { REPOSIÇÕES })+ \\
& \text { B3*(IDENTIFICAÇÃO - PT) + B4*(PARTICIPAÇÃO - } \\
& \text { ASSOCIAÇÃOBAIRRO } \left.)+ \text { B5* }{ }^{*} \text { PARTICIPAÇÃO - OP }\right)+ \\
& \mathrm{B} 6 *(\mathrm{HOMEM})+\mathrm{B} 7^{*}(\text { CONVERSA })+\mathrm{B} 8^{*}(\text { MEDIA })+ \\
& \text { B } 9 *(\mathrm{HGPE})+\mathrm{B} 10 *(\mathrm{IDADE})+\mathrm{B} 11^{*}(\mathrm{IDADE} 2)+ \\
& \text { B12*(INFORMAÇÃOGENERALIZADA) + } \\
& \text { B13*(IDEOLOGIA - ESQUERDA })+ \text { B14* }(\text { RAÇA })+ \\
& \text { B15*(RENDA })+B 16^{*}(\text { CONHECE NOMES DE } \\
& \text { CANDIDATO })+ \text { B17*(OPINIÃO - PRIVATIZAÇÃO })+ \\
& \text { B18*(OPINIÇÃO - REFORMA AGRÁRIA) + } \\
& \text { B19*(TERMÔMETRO - CANDIDATOS) + } \\
& \text { B20*(TERMÔMETRO - PARTIDO) + B23*(INFORMAÇÃO } \\
& \text { DEPUTADO FEDERAL) + R }
\end{aligned}
$$

Modelo do Segundo Nível

$$
\begin{aligned}
& \mathrm{B} 0=\mathrm{G} 00+\mathrm{G} 01 *(\text { RENDA MÉDIA DO BAIRRO })+\mathrm{U} 0 \\
& \mathrm{~B} 1=\mathrm{G} 10
\end{aligned}
$$


Equação de Três Níveis para Conhecimento sobre Nomes de Candidatos:

Modelo do Primeiro Nível

$$
\mathrm{Y}=\mathrm{P} 0+\mathrm{P} 1^{*}(\mathrm{TEMPO})+\mathrm{E}
$$

Modelo do Segundo Nível

$$
\begin{aligned}
& \mathrm{P} 0=\mathrm{B} 00+\mathrm{B} 01^{*}(\text { ESCOLARIDADE })+\mathrm{B} 02^{*}(\text { REPOSIÇÃO B })+ \\
& \text { B03*(REPOSIÇÃO C })+ \text { B04*(PARTICIPAÇÃO - } \\
& \text { ASSOCIAÇÃOBAIRRO })+ \text { B05*(PARTICIPAÇÃO - OP })+ \\
& \text { B06*(HOMEM })+ \text { B07*(ESTADO CIVIL }) \\
& + \text { B08*(SITUAÇÃO EMPREGO })+ \text { B09*(ESTUDANTE })+ \\
& \text { B010*(CONVERSA })+ \text { B011*(MEDIA) } \\
& + \text { B012*(HEG })+ \text { B013*(IDADE })+ \text { B014*(IDADE2 })+ \\
& \text { B015*(AVERSÃORISCO })+ \text { B016*(IDENTIDADE PT })+ \\
& \text { B017*(IDEOLOGIA - ESQUERDA })+ \text { B018*(ESTUDANTE) } \\
& + \text { B019*(APOSENTADO })+ \text { B020*(DONADECASA })+ \\
& \text { B021*(AFRO-BRASILEIRO) + B022*(RENDA })+ \text { R0 } \\
& \mathrm{P} 1=\mathrm{B} 10+\mathrm{B} 11^{*}(\text { PARTICIPAÇÃO - } \\
& \text { ASSOCIAÇÃOBAIRRO) + B12*(PARTICIPAÇÃO - } \\
& \text { ORÇAMENTO PARTICIPATIVO })+ \text { B13*(HOMEM) } \\
& + \text { B14*(CONVERSE })+ \text { B15*(MEDIA })+ \text { B16* }(\text { HGPE })+ \\
& + \text { B18*(AFRO-DESCENDENTE })+ \text { B20*(RENDA })+ \text { R1 }
\end{aligned}
$$

Modelo do Terceiro Nível

$$
\text { B00 = G000 + G001 (RENDA MÉDIA DO BAIRRO })+ \text { U00 }
$$




\section{ABSTRACT \\ Inequality and Political Information: The 2002 Brazilian Elections}

This article tests whether there were race, gender, and income-related biases in political participation and distribution of political information during the 2002 Brazilian elections. The importance of political information is not assumed, but verified empirically. The first step was thus to confirm which types of information more clearly affected voter turnout and choices. Having clarified the role of political information in the 2002 elections, the article proceeds to investigate whether there were biases in the distribution of information that affected political participation and choice. Data for this study were obtained from a single public opinion panel study conducted in two medium-sized Brazilian cities, and the findings indicate pervasive biases in the distribution of political information in Brazil.

Key words: political information; inequality; elections

\section{RÉSUMÉ}

Inégalités et Information Politique: Les Élections Brésiliennes en 2002

Dans cet article, on cherche à savoir si la race, le sexe et le salaire ont été responsables de biais dans la participation et la distribution de l'information politique aux élections brésiliennes de 2002. Tout d'abord on examine l'impact que l'information politique, sous toutes ses formes, peut avoir sur le comportement de l'électeur, sur sa décision de voter et son choix du candidat. Après avoir cerné ce rôle de l'information politique, on cherche à examiner les éventuelles distorsions dans la distribution de l'information. Les données de cette étude proviennent d'une seule source, un grand panel de l'opinion publique dans deux villes brésiliennes de taille moyenne. Les résultats montrent qu'on retrouve de forts biais dans la distribution de l'information politique au Brésil, surtout en ce qui concerne le sexe.

Mots-clé: information politique; inégalités; élections 